\title{
Reduced level of synapsin I protein in the rat striatum after intraventricular administration of proteasome inhibitors: preliminary studies
}

\author{
S. Wójcik, J.H. Spodnik, J. Sidor-Kaczmarek, J. Moryś \\ Department of Anatomy and Neurobiology, Medical University of Gdansk, Gdansk, Poland \\ [Received 9 October 2015; Accepted 11 October 2015]
}

\begin{abstract}
Background: We have recently described changes present in nigrostriatal terminals after intraperitoneal administration of MG-132 and changes that occur in the walls of the rat lateral ventricle after intraventricular administration of MG-132, lactacystin and epoxomicin - different classes of proteasome inhibitors. Substances that inhibit ubiquitin-proteasome system (UPS) activity, are intensively studied due to their potential role as novel therapeutic strategies in the treatment of cancer and ischaemia-reperfusion injury in the brain. The aim of this study is to determine the influence of intraventricular administration of MG-132, lactacystin and epoxomicin on the level in the rat striatum synapsin I - one of the most prominent neuron-specific phosphoproteins in the brain.

Materials and methods and Results: Two weeks after administration of studied proteasome inhibitors, substantial reduction (up to $80 \%$ ) of synapsin I was observed in the rat striatum. Because neurons, and especially dopaminergic ones, are sensitive to the depletion of proteasome function, we assume that observed synapsin I decrease may reflect changes in population of striatal neurons and/or nigrostriatal terminals.

Conclusions: Understanding of cellular mechanisms standing behind our findings needs further studies, and could provide valuable contribution to the discussion on the mechanisms linking UPS inhibition and survival of neurons. (Folia Morphol 2015; 74, 4: 428-433)
\end{abstract}

Key words: epoxomicin, lactacystin, MG-132, synapsin I, rat, neuronal nuclear antigen, Western blot

\section{INTRODUCTION}

Constant acquirement of new knowledge and information, and the development of new laboratory techniques and new diagnostic laboratory methods allow scientists to see well established analytical tools from a different perspective, and in many cases those tools can be used for a new purpose. Neuronal nuclear antigen (NeuN) antibody recognises a neuron-specific nuclear protein in vertebrates, and is commonly used as a reliable marker to detect most postmitotic neuronal cell types in neuroscience, developmental biology, and stem cell research fields as well as diagnostic histopathology [13]. However, NeuN antibody has been introduced in early 90's [18], its protein target, the Fox-3 gene product, was recognised about 15 years later [13]. The scientific group which revealed this, also pointed that a protein cross-reactive with anti-NeuN antibodies, present in immunoblots as $65-75 \mathrm{kDa}$ bands, is the synaptic vesicle protein, synapsin I. Further experiments on protein samples from synapsin II and synapsin III knockout mice and from compound knockout animals for synapsin I

Address for correspondence: S. Wójcik, MD, PhD, Department of Anatomy and Neurobiology, Medical University of Gdansk, ul. Dębinki 1, 80-210 Gdańsk, Poland, tel: +48 5834914 02, fax: +48 5834914 21, e-mail: swoj@gumed.edu.pl 
and II, and I, II and III supported the conclusion that the 65-75 kDa NeuN-cross-reactive bands are strictly dependent on the presence of synapsin I [16].

Synapsin I, one of the most prominent phosphoproteins in the brain, is the best characterised member of the synapsins family. In mammals, the synapsins consist of more than ten isoforms of neuron-specific phosphoproteins, which are encoded by three genes - designated synapsins I, II and III - and are thought to be involved in the regulation of neurotransmitter release. The synapsins, associated with the cytoplasmic surface of synaptic vesicles, are responsible for regulation of neurotransmitter release in presynaptic terminals of mature synapses and accelerate development of the nervous system [8]. It has been also proposed that, the synapsins may play a role in the formation and maintenance of synapses (synapsin I and II), synaptic vesicle fusion (synapsin I, II, and III) and its protein stabilisation (synapsin I and II), neurite elongation (synapsin I, II, and III) and neurogenesis (synapsin III) [24]. Lately, it has been postulated that synapsin cellular turnover is regulated by the ubiquitin-proteasome system (UPS) $[6,14]$, the main system responsible for protein degradation in eukaryotic cells, which has currently become attractive research topic due to its involvement in neurodegenerative pathogenesis during aging, the inflammatory response, and the dynamics of tumour development $[22,26]$.

We have recently described changes present in nigrostriatal terminals after intraperitoneal administration of MG-132 [28] and changes that occur in the walls of the rat lateral ventricle after intraventricular administration of MG-132, lactacystin and epoxomicin [27] - different classes of proteasome inhibitors. Substances that inhibit UPS activity are intensively studied due to their potential role as novel therapeutic strategies in the treatment of cancer and ischaemia-reperfusion injury in the brain [12]. The aim of this study is to determine the influence of intraventricular administration of selected covalent proteasome inhibitors - MG-132 (an example of peptide aldehydes), lactacystin (an example of $\beta$-lactones and derivatives) and epoxomicin (an example of epoxyketones) on level of synapsin I protein in the rat striatum.

\section{MATERIALS AND METHODS}

\section{Animals}

Twenty adult (postnatal day 90) male Wistar rats (initial weight between 230 and $270 \mathrm{~g}$ ) were used in this study. All rats were bred until they reached the appropriate age in the Tri-City Academic Laboratory Animal Centre - Research and Services Centre. All of the animals were bred behind a sanitary-hygienic barrier, which is supported by HEPA filters. The rats were kept in air-conditioned spaces under a constant temperature $\left(22 \pm 2^{\circ} \mathrm{C}\right)$ and humidity $(55 \pm 10 \%)$, with a defined lighting regimen (lights on from 7:00 a.m. to 7:00 p.m.). All rats were housed socially in polysulphone cages (size T. IV) with an area of 1875 $\mathrm{cm}^{2}$ and a height of $195 \mathrm{~mm}$ (3-4 animals per cage) strewn with powderless sawdust from deciduous trees. The rats were fed a standard food mixture for rodents, which is manufactured by SSNIFF (Spezialdiäten $\mathrm{GmbH}$, Germany). Both food and water were autoclaved before being served to the animals and water was available ad libitum. All of the rats were supplied to the Department Animal Centre 2 weeks before our experiments began and were housed in similar conditions. In this study, the rats' care and treatment was performed in strict accordance with the recommendations given in the "Guide for the care and use of laboratory animals" of the Polish National Committee on the Ethics of Animal Experiments. The experimental procedures were reviewed and approved by the $3^{\text {rd }}$ Local Committee on the Ethics of Animal Experiments in Gdansk (Local Committee of the Medical University of Gdansk - Permit Number: 08-2007). All efforts were made to reduce the number of animals and to minimise their suffering.

\section{Proteasome inhibitor administration}

The animals were randomly divided into four groups. All rats were anesthetised with an intraperitoneal administration of fentanyl $(1 \mathrm{mg} / \mathrm{kg})$ and dehydrobenzperidol $(0.2 \mathrm{mg} / \mathrm{kg})$. The animals were fixed in a stereotaxic frame (Trend Wells, USA) under sterile conditions, and after an incision in the skin, a small craniectomy was made above the selected cortical area. The cerebral cortex was exposed after an incision of the dura mater. A glass micropipette coated with silicone gel was inserted through the cerebral cortex into the right lateral ventricle, based on the stereotaxic coordinates from the bregma point: $0.6 \mathrm{~mm}$ posteriorly, $1.5 \mathrm{~mm}$ laterally, and $3.8 \mathrm{~mm}$ ventrally [19]. Pressure injections were made using a $5 \mu \mathrm{L}$ Hamilton syringe at a rate of $0.8 \mu \mathrm{L} / \mathrm{min}$. The first group, which is referred to as the controls $(n=5)$ in the subsequent text, consisted of animals that received a $4 \mu \mathrm{L}$ injection of $100 \%$ dimethyl sulphoxide 
(DMSO; Sigma-Aldrich, St Louis, MO). The second group is referred to as MG-132 ( $n=5)$, the third group as lactacystin $(n=5)$ and the fourth group as epoxomicin $(n=5)$ consisted of animals that received injections of $32 \mu \mathrm{g} \mathrm{MG-132} \mathrm{(Boston} \mathrm{Biochem}$ Inc.; cat \# I-130.5, lot \# 3570428), $20 \mu$ g lactacystin (Boston Biochem Inc.; cat \# I-115) or $4 \mu \mathrm{g}$ epoxomicin (Boston Biochem Inc.; cat \# I-110), respectively; all proteasome inhibitors were dissolved in $4 \mu \mathrm{L}$ of DMSO. The doses administered to the animals were based on those previously reported in the literature $[9,25]$. After each injection, the micropipette was held in place for at least $5 \mathrm{~min}$ to prevent leakage of the administered substance and then gently retracted, and the wound was surgically closed. The experimental endpoints have been set at 2 weeks after the surgery.

\section{Tissue collection and preparation for Western blot}

Two weeks after intraventricular administration of the studied substances, the rats were deeply anaesthetised with lethal doses of intraperitoneal injections of Nembutal ( $80 \mathrm{mg} / \mathrm{kg}$ of body weight). To obtain material suitable to perform Western blot analysis we used our previously published protocol [1]. Briefly, a total of 20 microdissected tissue samples (one from each animal) were obtained using a surgical microscope from the right striatum, the one next to the administration site. All the samples were manually homogenised on ice with a Potter-Elvehjem tissue grinder in 4 volumes of ice cold homogenisation buffer (20 mM Tris-HCl pH 7.5; $0.25 \mathrm{M}$ sucrose; 10 mM EGTA; 2 mM EDTA) containing protease inhibitors ( $1 \mathrm{mM}$ AEBSF, $0.8 \mu \mathrm{M}$ aprotynin; $50 \mu \mathrm{M}$ bestatin; $15 \mu \mathrm{M} \mathrm{E}-64,20 \mu \mathrm{M}$ leupeptin and $10 \mu \mathrm{M}$ pepstatin A). Samples were centrifuged at $4^{\circ} \mathrm{C}$, for $15 \mathrm{~min}, 14000 \mathrm{rpm}$. The supernatant was collected and centrifuged at $4^{\circ} \mathrm{C}$, for $30 \mathrm{~min}, 14000 \mathrm{rpm}$. To estimate the amount of protein in supernatant of the given sample the Lowry's method was used. Denaturated $40-\mu \mathrm{g}$ protein samples were electrophoretically separated on $12 \%$ Tris-SDS gels with Tris-glycine electrophoresis buffer and subsequently transferred onto a nitrocellulose membrane by semi-dry electroblotting. Quality of transfer was controlled by Ponceau S staining. The membranes were then blocked with 3\% nonfat dry milk in tris-buffered saline (TBS) buffer (10 mM Tris $\mathrm{pH}$ 7.6; $150 \mathrm{mM} \mathrm{NaCl}$ ) for $2 \mathrm{~h}$ and incubated overnight at $4^{\circ} \mathrm{C}$ with primary antibody: monoclonal mouse anti-NeuN antibody, clone A60 (MAB377 Chemicon; 1:500 dilution) diluted in 1.5\% milk in TBST (TBS buffer supplemented with $0.05 \%$ Tween 20 ). Having been washed $3 \times 10 \mathrm{~min}$ with TBS, the blots were incubated for $2 \mathrm{~h}$ with secondary rabbit anti-mouse antibody, horseradish peroxidase conjugate (1:50000; Sigma, USA) diluted in TBST. The internal standard of $\beta$-actin was used under the abovementioned conditions with mouse monoclonal anti- $\beta$-actin primary antibody (1:30 000; Sigma, USA) and rabbit antimouse IgG, horseradish peroxidase-conjugated antibody (1:50 000; Sigma, USA). A chemiluminescent signal was developed using the SuperSignal West Pico chemiluminescent system (Pierce, USA) and visualised on an X-ray film.

\section{Quantitative analysis}

In order to assess the level of synapsin I protein expression in the striatum, X-ray films were scanned and the optical density (OD) of bands was evaluated using Image J 1.38 software (National Institutes of Health, USA). Relative OD ratios were calculated by comparing the OD of synapsin I of each sample with the OD of its internal standard ( $\beta$-actin). The differences in the relative OD of synapsin I between studied groups were evaluated.

\section{Statistical analysis}

Statistical analysis was performed using GraphPad InStat version 3.0a for Windows (GraphPad Software, San Diego, CA). In the first step Bartlett test and Kolmogorov-Smirnov test were performed to test the homogeneity of standard deviations (SD) and normal distribution of the data, respectively. Following significant one-way ANOVA, the post hoc Dunnett test was performed to assess differences between control and each of experimental groups. $\mathrm{P}<0.05$ was considered statistically significant. The results of Western blot analyses (Fig. 1) were expressed as mean relative $\mathrm{OD} \pm \mathrm{SD}$.

\section{RESULTS}

Antibody anti-NeuN, clone A60 (MAB377, Chemi(on), recognises at least two major protein species migrating at approximately $45-50 \mathrm{kDa}$, by western of full brain extracts. In addition to the $45-50 \mathrm{kDa}$ NeuN doublet, some neuronal cells lysate preparations show by western additional reactive bands at $\sim 66 \mathrm{kDa}$, and between $\sim 70-90 \mathrm{kDa}[5,13,16]$. In our study, in the supernatant obtained from rat's striatum samples, the "classic" NeuN doublet species below 50 kDa was depleted, and only doublet of reactive bands at 

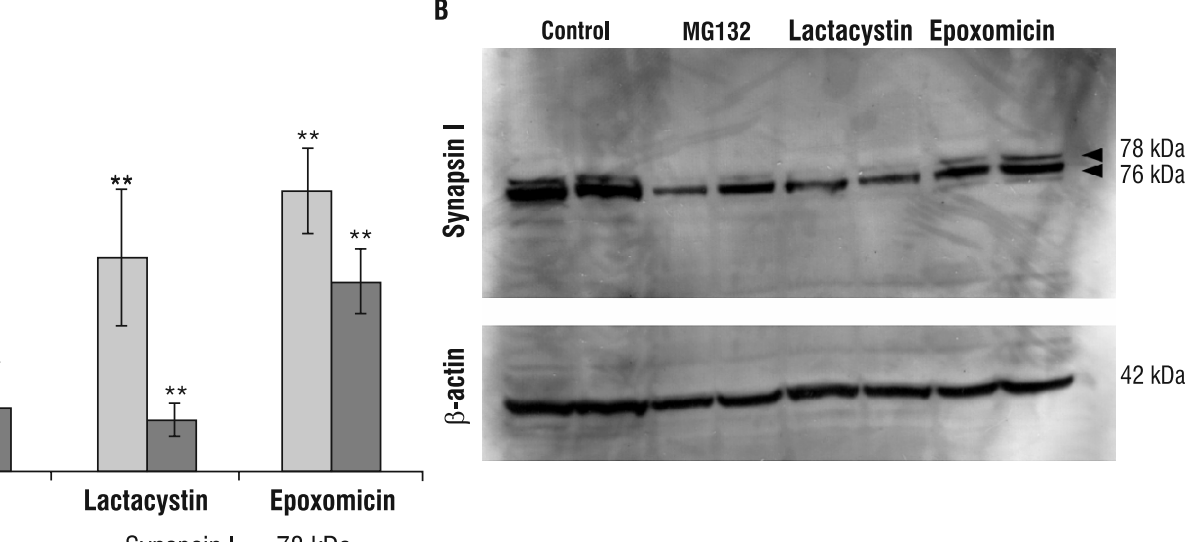

Synapsin I $-76 \mathrm{kDa}$

Synapsin I $-78 \mathrm{kDa}$

Figure 1. Densitometric analysis of synapsin I protein level in the rat's striatum 2 weeks after intraventricular administration of proteasome inhibitors: MG-132, lactacystin or epoxomicin. The protein level is presented as a ratio of the optical density of studied protein to the internal standard of $\beta$-actin (relative optical density) (A). Significant decrease in the synapsin I protein level after proteasome inhibitors administration versus control is indicated by asterisk $\left({ }^{* *} ; p<0.01\right)$. A representative blot, probe with antibody anti-neuronal nuclear antigen, with visible bands with molecular weight corresponding to synapsin I, is shown (B).

approximately 76 an $78 \mathrm{kDa}$ was observed (Fig. 1), which was in accordance with previously published reports [5, 13]. Study performed on P19 cells and adult mice nervous tissue by Kim et al. [13] showed that the peptide sequences from the upper band included a sequence unique to synapsin la while peptide sequences from the lower band are all common to isoforms la and $\mathrm{lb}$. Therefore, the lower band could be synapsin Ib or a proteolytic fragment of synapsin la. Also, according to other studies performed on protein extracts of the early developing and adult mice brains [16], bands with this molecular weight present after western blot incubation with anti-NeuN antibody recognises synapsin I in postnatal period, while at prenatal period at this level it also recognises another protein, most likely R3hdm2 [16]. On the basis of listed above data we are confident, that doublet of reactive bands observed at approximately 76 and $78 \mathrm{kDa}$ is synapsin I.

Two weeks after intraventricular administration of proteasome inhibitors, in each experimental group significant differences were found in the OD of synapsin I protein within the striatum as compared with control group (Fig. 1). After MG-132 administration, the OD of synapsin I $76 \mathrm{kDa}$ band was $61 \%$ lower $(p<0.01)$, while the OD of synapsin I $78 \mathrm{kDa}$ band was $76 \%$ lower $(p<0.01)$. After lactacystin administration, the OD of synapsin I $76 \mathrm{kDa}$ band was $42 \%$ lower $(p<0.01)$, while the OD of synapsin I $78 \mathrm{kDa}$ band was $81 \%$ lower $(p<0.01)$. The smallest, but significant differences were observed after epoxomicin administration, the OD of synapsin I $76 \mathrm{kDa}$ band was $24 \%$ lower $(p<0.01)$, while the OD of synapsin I $78 \mathrm{kDa}$ band was $29 \%$ lower $(p<0.01)$.

The analysis of synapsin I intensity on the brain sections stained with anti-NeuN antibody was not planned, because according to previous studies [13, 16] this antibody does not recognise synapsin I on immunohistochemically stained sections.

\section{DISCUSSION}

Decreased level of synapsin I, similar to the one described above, has been reported formerly in naturally occurred neuropathological conditions such as Alzheimer's disease $[10,20]$, or during HIV-1 infection [7]. Significant depletion of synapsin I, was also observed in experimental models of brain trauma such as transient middle cerebral artery occlusion [21] and mild brain fluid percussion injury [23]. Initially, the decrease of synapsin I observed during Alzheimer's disease in the hippocampal formation [20], and entorhinal cortex - even in cases characterised by the earliest clinically detectable stage of the disease [10], was considered as an effect of a nonspecific loss of whole synapses. However, more recently, investigation of changes in the expression of several presynaptic and postsynaptic proteins in primary neurons treated with a low-molecular weight and high-molecular weight $\beta$-amyloid oligomers, revealed that both oligomers significantly reduced expression of several presynaptic 
proteins, including synapsin [11]. Since strong evidence exists for a central role of $\beta$-amyloid oligomers in the pathogenesis of Alzheimer's disease [3], changes in synapsin I levels observed in this disease seems to be specific response for pathological events triggered by presence of $\beta$-amyloid oligomers. As a specific change within viable nerve endings is treated also the decrease of synapsin $\mathrm{lb}$ in nerve endings associated with HIV-1 infection. It has been proposed that depletion of synapsin I is linked to an abnormal regulation of the reserve pool of presynaptic vesicles of brain neocortex [7] and possibly causes long-term synaptic depression. Experimentally induced transient middle cerebral artery occlusion resulted in decreased mRNA levels of genes encoding synapsin la in the ischaemic cortex [21]. The authors of this study postulated that low level of level of this transcript could participate in disrupt neurotransmitter release and, thus, long-term potentiation after transient middle cerebral artery occlusion.

It has to be noted that the results of majority experimental studies $[6,11,14,23]$ link changes in the level of synapsin I protein with the activity of proteasome. After the mild brain fluid percussion injury as an explanation of almost $60 \%$ reduce of synapsin I levels authors postulated proteasome activation via elevations in protein oxidation [23]. Used in the studies the proteasome inhibitor MG-132 attenuated synapsin I loss caused by $\beta$-amyloid oligomers [11], while lactacystin blocked synapsin decrease present during transcription-dependent long-term synaptic depression induced by administration of the neuropeptide Phe-Met-Arg-Phe-NH2 (FMRFa) [6]. Interesting data has been published by Lazarevic et al. [14]. Treatment of cultures of control and silenced rat neurons with MG-132 for $6 \mathrm{~h}$ resulted in an increase in total cellular levels of cytomatrix-associated proteins Bassoon, ELKS/CAST, Munc13-1, RIM, and synapsin in control and silenced cultures. However, treatment with MG-132 for 24 or $48 \mathrm{~h}$ did not result in increase in protein levels as expected, but led to a downregulation of multiple known UPS targets (e.g., RIM, Munc13-1, and liprin- $\alpha$ ) and other presynaptic and postsynaptic scaffolding proteins such as Bassoon, ELKS/CAST, Homer, and synapsin. Authors concluded that the UPS regulates levels of cellular proteins in an extremely specific manner, and it is influenced by the activity status of neuronal networks, which may also explain results obtained in our study.

\section{CONCLUSIONS}

Described in the present manuscript substantial reduction of the striatal synapsin I - one of the most prominent neuron-specific phosphoproteins in the brain - observed 2 weeks after intraventricular administration of proteasome inhibitors, is in accordance with previous in vivo and in vitro studies which indicate that neurons are very sensitive to the depletion of proteasome function $[2,4,17,28]$. Because dopaminergic neurons are especially fragile to this depletion, and substantial loss of dopaminergic terminals in the striatum after proteasome inhibitors administration has been reported [15, 28], we assume that observed synapsin I level decrease may reflect changes in population of striatal neurons and/or nigrostriatal terminals. We realise that explanation of cellular mechanisms standing behind our findings needs more intensive studies, but we hope that presented data may be a valuable contribution to the discussion on the mechanisms linking UPS inhibition and survival of neurons.

\section{ACKNOWLEDGEMENTS}

This work was supported by a Polish Ministry of Science and Higher Education grant - NN401 005735 (to SW) and by a statutory (ST-11) grant from the Polish Ministry of Science and Higher Education ST-0011/07/211. The funders had no role in the study design, data collection and analysis, decision to publish, or preparation of the manuscript.

\section{REFERENCES}

1. Badowska-Szalewska E, Ludkiewicz B, Sidor-Kaczmarek J, Lietzau G, Spodnik JH, Swietlik D, Domaradzka-Pytel B, Morys J (2013) Hippocampal interleukin-1beta in the juvenile and middle-aged rat: response to chronic forced swim or high-light open-field stress stimulation. Acta Neurobiol Exp, 73: 364-378. doi:7326 [pii]

2. Bedford L, Hay D, Devoy A, Paine S, Powe DG, Seth R, Gray T, Topham I, Fone K, Rezvani N, Mee M, Soane T, Layfield R, Sheppard PW, Ebendal T, Usoskin D, Lowe J, Mayer RJ (2008) Depletion of $26 \mathrm{~S}$ proteasomes in mouse brain neurons causes neurodegeneration and Lewy-like inclusions resembling human pale bodies. J Neurosci, 28: 8189-8198. doi: 10.1523/JNEUROSCI.2218-08.2008.

3. Brener O, Dunkelmann T, Gremer L, van Groen T, Mirecka EA, Kadish I, Willuweit A, Kutzsche J, Jurgens D, Rudolph S, Tusche $\mathrm{M}$, Bongen P,Pietruszka J, Oesterhelt $\mathrm{F}$, Langen $\mathrm{KJ}$, Demuth HU, Janssen A, Hoyer W, Funke SA, Nagel-Steger L, Willbold D (2015) QIAD assay for quantitating a compound's efficacy in elimination of toxic Abeta oligomers. Sci Rep, 5: 13222. doi: 10.1038/srep13222. 
4. Ding Q, Dimayuga E, Martin S, Bruce-Keller A, Nukala V, Cuervo AM, Keller JN (2003) Characterization of chronic low-level proteasome inhibition on neural homeostasis. J Neurochem, 86: 489-497.

5. Dredge BK, Jensen KB (2011) NeuN/Rbfox3 nuclear and cytoplasmic isoforms differentially regulate alternative splicing and nonsense-mediated decay of Rbfox2. PLoS One, 6: e21585. doi: 10.1371/journal.pone.0021585.

6. Fioravante D, Liu RY, Byrne JH (2008) The ubiquitin-proteasome system is necessary for long-term synaptic depression in Aplysia. J Neurosci, 28: 10245-10256. doi: 10.1523/JNEUROSCI.2139-08.2008.

7. Gelman BB, Nguyen TP (2010) Synaptic proteins linked to HIV-1 infection and immunoproteasome induction: proteomic analysis of human synaptosomes. J Neuroimmune Pharmacol, 5: 92-102. doi: 10.1007/s11481-009-9168-0.

8. Greengard P, Valtorta F, Czernik AJ, Benfenati F (1993) Synaptic vesicle phosphoproteins and regulation of synaptic function. Science, 259: 780-785.

9. Hamano T, Gendron TF, Ko LW, Yen SH (2009) Concentration-dependent effects of proteasomal inhibition on tau processing in a cellular model of tauopathy. Int J Clin Exp Pathol, 2: 561-573.

10. Ho L, Guo $Y$, Spielman L, Petrescu O, Haroutunian V, Purohit D, CzernikA, Yemul S, Aisen PS, Mohs R, Pasinetti GM (2001) Altered expression of a-type but not b-type synapsin isoform in the brain of patients at high risk for Alzheimer's disease assessed by DNA microarray technique. Neurosci Lett, 298:191-194.

11. Jang BG, In S, Choi B, Kim MJ (2014) Beta-amyloid oligomers induce early loss of presynaptic proteins in primary neurons by caspase-dependent and proteasomedependent mechanisms. Neuroreport, 25: 1281-1288. doi: 10.1097/WNR.0000000000000260.

12. Kandilis AN, Karidis NP, Kouraklis G, Patsouris E, Vasileiou I, Theocharis S (2014) Proteasome inhibitors: possible novel therapeutic strategy for ischemia-reperfusion injury? Expert Opin Investig Drugs, 23: 67-80. doi:10.1517/13543 784.2013.840287.

13. Kim KK, Adelstein RS, Kawamoto S (2009) Identification of neuronal nuclei (NeuN) as Fox-3, a new member of the Fox-1 gene family of splicing factors. J Biol Chem, 284: 31052-31061. doi: 10.1074/jbc.M109.052969.

14. Lazarevic V, Schone C, Heine M, Gundelfinger ED, Fejtova A (2011) Extensive remodeling of the presynaptic cytomatrix upon homeostatic adaptation to network activity silencing. J Neurosci, 31: 10189-10200. doi: 10.1523/ JNEUROSCI.2088-11.2011.

15. Lorenc-Koci E, Lenda T, Antkiewicz-Michaluk L, Wardas J, Domin H, Smialowska M, Konieczny J (2011) Different effects of intranigral and intrastriatal administration of the proteasome inhibitor lactacystin on typical neurochemical and histological markers of Parkinson's disease in rats. Neurochem Int, 58: 839-849. doi: 10.1016/j. neuint.2011.03.013.
16. Maxeiner S, Glassmann A, Kao HT, Schilling K (2014) The molecular basis of the specificity and cross-reactivity of the NeuN epitope of the neuron-specific splicing regulator, Rbfox3. Histochem Cell Biol, 141: 43-55. doi:10.1007/ s00418-013-1159-9.

17. Miwa H, Kubo T, Suzuki A, Nishi K, Kondo T (2005) Retrograde dopaminergic neuron degeneration following intrastriatal proteasome inhibition. Neurosci Lett, 380: 93-98. doi: 10.1016/j.neulet.2005.01.024.

18. Mullen RJ, Buck CR, Smith AM (1992) NeuN, a neuronal specific nuclear protein in vertebrates. Development, 116: 201-211.

19. Paxinos G, Watson C (1998) The rat brain in stereotaxic coordinates edn. 4th Ed. Academic, San Diego, London.

20. Qin S, Hu XY, Xu H, Zhou JN (2004) Regional alteration of synapsin I in the hippocampal formation of Alzheimer's disease patients. Acta Neuropathol, 107: 209-215. doi: 10.1007/s00401-003-0800-4.

21. Raghavendra Rao VL, Bowen KK, Dhodda VK, Song G, Franklin JL, Gavva NR, Dempsey RJ (2002) Gene expression analysis of spontaneously hypertensive rat cerebral cortex following transient focal cerebral ischemia. J Neurochem, 83: 1072-1086.

22. Rogers N, Paine S, Bedford L, Layfield R (2010) Review: the ubiquitin-proteasome system: contributions to cell death or survival in neurodegeneration. Neuropathol Appl Neurobiol, 36: 113-124. doi: 10.1111/j.13652990.2010.01063.x.

23. Szabo Z, Ying Z, Radak Z, Gomez-Pinilla F (2010) Voluntary exercise may engage proteasome function to benefit the brain after trauma. Brain Res, 1341: 25-31. doi: 10.1016/j. brainres.2009.01.035.

24. Valtorta F, Pozzi D, Benfenati F, Fornasiero EF (2011) The synapsins: multitask modulators of neuronal development. Semin Cell Dev Biol, 22: 378-386. doi: 10.1016/j. semcdb.2011.07.008.

25. Villamar-Cruz O, Manjarrez-Marmolejo J, Alvarado R, Camacho-Arroyo I (2006) Regulation of the content of progesterone and estrogen receptors, and their cofactors SRC- 1 and SMRT by the $26 \mathrm{~S}$ proteasome in the rat brain during the estrous cycle. Brain Res Bull, 69: 276-281. doi: 10.1016/j.brainresbull.2005.12.006.

26. Wojcik S (2013) Crosstalk between autophagy and proteasome protein degradation systems: possible implications for cancer therapy. Folia Histochem Cytobiol, 51: 249-264. doi: 10.5603/FHC.2013.0036.

27. Wojcik S, Spodnik JH, Dziewiatkowski J, Spodnik E, Morys J (2015) Morphological changes within the rat lateral ventricle after the administration of proteasome inhibitors. PLoS One, 2015; 10: e0140536. doi: 10.1371/journal. pone.0140536. eCollection 2015.

28. Wojcik S, Spodnik JH, Spodnik E, Dziewiatkowski J, Morys J (2014) Nigrostriatal pathway degeneration in rats after intraperitoneal administration of proteasome inhibitor MG-132. Folia Neuropathol, 52: 41-55. 